\title{
Good Practices in Strategic Environmental Assessment Processes under the Brazilian Practitioners' Vision
}

\author{
Antonio W. L. da Silva ${ }^{*}$, Marinilse Netto ${ }^{2}$, Paulo Selig ${ }^{3}$, Alexandre Lerípio ${ }^{4}$ \\ ${ }^{1}$ Santa Catarina State University-UDESC, Chapecó, Brazil \\ ${ }^{2}$ Community University of the Region of Chapecó-Unochapecó, Chapecó, Brazil \\ ${ }^{3}$ Federal University of Santa Catarina-UFSC, Florianópolis, Santa Catarina, Brazil \\ ${ }^{4}$ University of Vale do Itajaí-Univali, Univali, Brazil \\ Email: *awls12@hotmail.com, mari.netto@hotmail.com, pauloselig@gmail.com, leripio@terra.com.br
}

How to cite this paper: da Silva, A.W.L., Netto, M., Selig, P. and Lerípio, A. (2018) Good Practices in Strategic Environmental Assessment Processes under the Brazilian Practitioners' Vision. Journal of Environmental Protection, 9, 720-735.

https://doi.org/10.4236/jep.2018.96045

Received: March 6, 2018

Accepted: May 28, 2018

Published: May 31, 2018

Copyright (C) 2018 by authors and Scientific Research Publishing Inc. This work is licensed under the Creative Commons Attribution International License (CC BY 4.0)

http://creativecommons.org/licenses/by/4.0/

\begin{abstract}
The use of good practices (GP) can improve the technical quality and, as a consequence, the outcome of the Strategic Environmental Assessment (SEA) process, increasing its effectiveness. This study aimed to present GP pointed out by Brazilian practitioners (members of the SEA development teams) from the perspective afforded by their participation in processes of this tool. The data were collected through personal interviews with 11 professionals responsible for preparing a total of 17 SEAs, who were asked about what measures adopted in the SEA could be considered BP. The responses were audio-recorded, transcribed, and had their content assessed by Content Analysis technique. Nine GP were highlighted by practitioners. The GP indicated represent a valuable contribution to the improvement of future use of SEA, either in Brazil or in other countries, because they are the result of consolidated experience in real cases of application of the tool.
\end{abstract}

\section{Keywords}

Best Practices, Environmental Management, Environmental Policy, Knowledge Management, Sustainability

\section{Introduction}

Strategic Environmental Assessment (SEA) is an environmental policy instrument that aims to incorporate elements of sustainability throughout the policy, planning and program (PPP) process, so that these elements will be considered 
in decision-making on such initiatives. In Brazil, SEA is not included in the national legal system and its realization is optional, except in cases where the requirement comes from funding agencies [1]. The first SEA performed in the country dates back to 1997 and in these twenty years of application of the tool, only about 40 SEAs were developed [2]. The literature has pointed out that national processes/reports contain flaws and limitations [3] [4] [5], but, on the other hand, there is a continuous and lively debate about the practice of SEA [2].

As a seminal concept of Knowledge Management, good practices (GP) are structured information (ranging from analytical reports to narratives) about successful experiences in certain contexts, regarding issues recognized as relevant [6]. Based on the "good example" principle, GP involve processes and methodologies that have proven to work well and produce adequate results, and are therefore recommended as a model [7].

Repertoires of good practices are widely acknowledged as a good policy instrument. Quite differently from rules, norms, directives, precepts, etc., "good practices" apparently inspire a general and legitimizing consensus.

"Good practice" is good in itself [6] (p. 1069).

The use of GP can produce several positive effects [8]: 1) identify and replace inappropriate practices; 2 ) raise performance closer to the best possible; 3 ) avoid "reinventing the wheel"; 4) minimize the rework caused by the use of poor methods; and 5) save costs as a consequence of better productivity and efficiency. Thus, GP are an important source of answers and solutions for operational and managerial issues, and its application becomes a qualitative differential by providing results from previously tested "ways of doing".

The importance of using GP in SEA is undeniable. It is possible to verify a clear link between GP and procedural effectiveness in environmental assessments, as GP provide standards for practitioners (members of SEA teams) and ensure information for proper decision making [9]. There is a need to identify weaknesses in SEA approaches and "focus attention on best practices" [10] (p. 310). Therefore, it is necessary "to make 'best practice' even more 'common' practice" [11] (p. 263). GP integrate a context of knowledge exchange and shared learning [12]. It is known that the use of GP does not guarantee a good SEA, but it is certainly a way to do so.

A decade ago, João [13] says that "best-practice examples are still rare" (p. 697). In contrast to this statement, in recent years, the number of papers that discuss and demonstrate the application of GP within the scope of the SEA has increased [12] [14]-[20] and the GP "are fairly well developed" [21] (p. 57). It should be noted, however, that a great part of these materials is the result of the exclusive vision of researchers and specialists, without considering the perspective of practitioners who, when working in the preparation of SEA studies, have particular experience and capacity of defining and delimiting GP. In addition, most examples of GP come from work in developed countries, with a long tradi- 
tion of SEA. Studying the tool in the face of other realities, including in developing countries, will enable consolidation of knowledge about what constitutes, at the international level, a SEA focused on GP [21].

Clearly, further exploration of what constitutes GP, particularly in developing countries, is warranted. Thus, the study reported in the present paper aims to present good practices as defined by Brazilian practitioners, based on the perspectives they developed as a result of their participation in SEA processes.

\section{Methodology}

This is a study with a qualitative approach, developed through interviews carried out with professionals that integrated the technical staff of SEA teams ("practitioners"). The interviews aimed to gather information about the vision, experience and perceptions of practitioners, that is, the reality seen through the eyes of protagonists of a practical application of the tool.

To select practitioners, it was necessary first to select organizations that had developed SEA processes. The size of the sample (number of organizations/practitioners) was defined so that the chosen organizations had conducted more than half of the SEA processes carried out in Brazil until that moment (32 in total).In addition, the research prioritized the organizations with participation in more than one SEA process, due to their greater degree of experience, as well as to permit the approach of different contexts where SEAs were realized. The choice also aimed for geographic diversity, selecting those organizations that worked in different regions of the country. It was possible to meet all criteria with eight organizations, which together had conducted 17 SEAs (between 2002 and 2011).

Each of these organizations was contacted by the researchers with a view to defining the practitioner to be interviewed. Respondents were invited by phone or e-mail. In some cases, the practitioner proposed that the meeting include other practitioners from the same team, what was accepted by the study, totaling 11 interviewees. The group of respondents included four men and seven women, all with higher education (undergraduate, graduate or postgraduate degree), who act or have acted as managers or technical consultants of public or private environmental companies.

The interviews were conducted in eight face-to-face sessions, in seven Brazilian capitals, between July and August 2013. The date, time and place of interview were chosen by the practitioners. Each interview lasted one and a half to two hours. Before the beginning of the interview, the practitioner(s) who were to be interviewed received an "Informed and Free Consent Form", which contained information about the research, the interview activity and the ethical principles underlying the work, and assured participants of their anonymity. After the participants indicated their consent to participate in the study by signing the document, the interview began. To ensure anonymity, each practitioner was identified by a letter.

The research instrument was a standardized and semi-structured questionnaire composed of open questions. The present paper addresses only one ques- 
tion from this questionnaire: "What measures adopted in the SEA could be considered 'good practices'?" There were no suggestions made about any specific GP, that is, all were mentioned spontaneously by the interviewees.

The interviews were audio recorded, with the consent of the interviewees. The recordings have been transcribed literally. The Content Analysis technique was applied to the content of the answers. The most representative excerpts from the interviews were selected to demonstrate the practitioners' knowledge, perception and opinion regarding each of the GP indicated.

\section{Results and Discussion}

Several GP were highlighted by practitioners as capable of improving SEA processes. The following are the nine GP considered most relevant.

\subsection{GP 1-Adequacy of the Term of Reference}

For [9], in environmental assessments, a GP is the definition of a Term of Reference (TR) that specifies the scope of the work, its content and the methods to be employed. TR is an instrument developed in the pre-assessment stage and often before hiring the team that will lead to SEA, i.e. practitioners usually have little or no influence over the document. A poorly produced TR can cause serious damage to the conduct of the process and to the final result of the assessment. Many of the shortcomings of the SEAs were due to inadequacy of the TR [22]. Developing an appropriate TR is definitely a GP [23].

We had a Term of Reference to follow. Often we disagreed, because the Term of Reference had been made based on a SEA focused on another sector [oil]. So there were issues that had nothing to do with the program we were analyzing. (Practitioner A)

The TR should establish the guidelines for the assessment, but at the same time, it must be adequately flexible to allow practitioners to act within the technical context. Sometimes the TR becomes a "straitjacket" by imposing certain requirements, and its fulfillment is only pro forma.

The participation of specialists in the elaboration of TR is fundamental and practitioners should be encouraged to dialogue with the contracting party in order to improve it [22]. Therefore, the participation of the SEA team in the process of constructing the TR, if possible, constitutes a GP.

You have to discuss the Term of Reference very much. It is not a very easy thing. Usually you do not know the sector, you do not know the region, so the Term of Reference is a critical point. Then you "walk" through it. This aspect has to be very clear between the executors and the contractors, so as not to have controversy, not to be charged. (Practitioner B)

\subsection{GP 2-Formation of the Drafting Team}

Several interviewees referred to the SEA's drafting team as a critical point and, at 
the same time, as a GP in the processes in which they participated. Experienced practitioners can add value to the methodological aspect of the assessment [22]. The team's constitution must consider the multidisciplinary, iterative and cyclical nature of the SEA, observing the three fundamental aspects of the application-technical, procedural and communicational [16].

The importance of team building is highlighted by practitioners who have participated in different SEA processes:

Team is something that does not "fall from the sky". You must have the understanding that you can change the team. Sometimes there is no way, it has to change. If you realize at the beginning of the job that you are not going to walk with that person-not due to capacity, it is a matter of skill-then you must have the clarity to change. Otherwise, that component [subject of assessment under the responsibility of that person] will be impaired. (Practitioner B)

We have to know who to work with. Know the resistance of people to know how to break this resistance or even change. It is important that the person working in an SEA is able to listen, accept, argue, defend their idea, but to be open if they need to change. Working with radical people is very difficult and does not "give a product". (Practitioner C)

The number of members of the team is another element that deserves particular attention:

In an EIA [Environmental Impact Assessment] there is always a great team. It has several biologists, because one looks at the entomofauna, another the herpetofauna, etc., specifically by area. They are people who do the work, the coordinator goes on synthesizing, transforming into text, and puts it into the EIA. In SEA we started out a bit like this, having three, four biologists, thinking that there was this question of analysis, of diagnosis, which is very difficult. There was a big team, about thirteen people at the beginning. The discussions were not productive. We argued, argued, and we never came to a "common denominator". Then, we simplified this team and closed in a total of six people. We have seen that the team cannot be very big, because this interdisciplinary interaction has to happen constantly, in the day to day, and if the team is very big, it is lost. (Practitioner A)

The way the team works, or its "posture", is highlighted with a strong point:

Even being a small team, this open posture, with respect for knowledge and allowing the dialogue, this convergence was fundamental. (Practitioner D)

The interviewees also highlighted the potential importance of specificity of knowledge, usually associated with a higher academic degree of the scientist, for in the "quality" of the final product:

We usually require that the person has a doctorate, a master's degree, and, 
in fact, sometimes the person has a very specific knowledge that we cannot employ in an SEA. (Practitioner C)

These team building issues clearly exemplify GP that are not detected through the evaluation of a report, but only through lessons learned by those who have effectively participated in SEA elaboration processes.

\subsection{GP 3-Implementation of the SEA in Parallel to the Preparation of the PPP}

SEA is a tool that is characterized by methodological flexibility and different approaches [24]. In the "integrated" or "parallel SEA" model, the planning (elaboration of a PPP) and its respective environmental assessment occur simultaneously, with interaction and integration between both. This system facilitates the incorporation of elements of sustainability, influencing the selection of environmentally adjusted alternatives in the initial stages of decision making [12]. It is, in fact, a crucial procedure for the success of both processes [4] [25]. In this way, it constitutes a GP.

One of the measures was the decision to make the SEA at the time the plan is being drawn up. I think this is good practice. This refers to the good practices that Partidário [Portuguese researcher] advocates. It was essential we have worked in parallel. (Practitioner E)

The environmental assessment has to start with the program itself and not at a later stage. If the government thinks strategically in a program, the environmental step has to be inserted. In the budgetary sphere, resources are released to make a project, and after, environmentally, it becomes unworkable. Then, we try to mend something that is difficult to achieve, when the environmental assessment could have identified these difficulties. Today, in Brazil, it is left to identify this in the stage of EIA. (Practitioner F)

The effect that this has on the qualitative improvement of the plan was pointed out by one interviewee:

If SEA is done in this way [parallel to the plan], we, who were doing the [plan], had a lot of work, because as the SEA identified some problems that we had not identified, the Ministry [contracting entity] said: "how you did they arrive at these solutions if they did not identify this problem in the diagnosis?" So, we had to go back and put this type of analysis, the problem, into the diagnosis [of the plan]. (Practitioner D)

Although this GP has clear positive effects, it should be noted that its employment is still limited. In a work analyzing 20 Portuguese SEAs, it was found that $80 \%$ were not developed simultaneously with the PPP and in other cases, this was only partially done [18].

\subsection{GP 4-Involvement of the Contracting Entity}

The participation of professionals from the contracting entity of the SEA during 
the study in a manner that is integrated with the SEA team is another GP highlighted by the practitioners. It should be noted that the contracting entity may be the proponent of the initiative under evaluation (entrepreneur) or the governmental control agency. In the case of being the proponent itself, the development of the SEA in parallel to the PPP (previous GP) can potentiate this interaction. In three SEAs carried out in Brazil, collaborative dialogue and the dissemination of knowledge among entrepreneurs and/or government sectors led to advances in terms of environmental governance [4].

A good practice is the contact with the environmental agency that requested the study or with any other body that has requested it. It is important to do this during the elaboration and not only at the end, when delivering the product ready. It is a very positive experience when it is done this way. (Practitioner G)

An interviewee highlights that in an SEA the contracting entity did not directly follow the study but hired a third company to do so:

An aspect I consider important is the participation of the contracting [entity] aiming to learn. Those who hired us had to have a team accompanying the work on a day-to-day basis, as a check-up, but that did not exist. The contracting entity accompanied our work through another entity. If the contracting hire another SEA, it will have to hire the entity again. There was no person from the contracting who did this follow-up. I consider this very damaging. We had the knowledge, we learned. But the contracting itself cannot make another SEA. (Practitioner A)

There are also situations in which the contracting entity oversees the work, but without effective involvement:

In "our" SEA has had a periodic monitoring by a restricted group, but not a working group that builds together. (Practitioner $\mathrm{H}$ )

The constant presence of the "eyes of the client" throughout the SEA facilitates contact between the parties, the contribution of information and the exchange of experiences and knowledge that may prove essential to the work. The monitoring of the study provides learning and critical awareness for the contracting entity, enhancing the quality of the decision making, and provides better conditions for the monitoring of the PPP when it is implemented.

\subsection{GP 5-Supervision and Support of Another SEA Team}

One of the basic principles of SEA is to implement an independent review system that provides quality control of the process [15], although this is not often done [1]. Some interviewees mentioned as positive the supervision and/or support provided by external, specialized consultants with experience in conducting SEA processes. Such supervision and support, considered as a GP [9], involves two Knowledge Management techniques- "peer review" and "peer assistance" 
[8]. The result is a valuable exchange of knowledge and lessons learned, associated with mentoring an SEA team who may be less familiar with the tool and its methodology.

The participation of other SEA teams, as a specialized group and with previous experiences in SEA, to interact and build together with us, was very rich. I think this is a good practice. (Practitioner I)

It was important the participation of other SEA staff guiding us. Otherwise, we would not be able to "close" this SEA the way it was "closed". (Practitioner A)

Involvement may occur on the initiative of one or both groups, but is most often triggered by provisions previously established at a contractual level and is therefore compulsory. A practitioner with a track record as a "supervisor" sees advantages for both parties:

You have a discussion at the same level. They are doing the work and you have, in a way, accumulated knowledge, and you discuss, interact, and only improve. I find this exchange very interesting-you sit down with an experienced staff and discuss everything. (Practitioner B)

The joint action of the two SEA teams, although one acts as a reviewer, allows an undeniable "sum of looks" and a cognitive and technical synergy, leading to the improvement of the SEA process as a whole.

\subsection{GP 6-Evaluation of the Institutional Capacity to Follow up the SEA and the PPP}

The implementation of an SEA presupposes that its indications or recommendations will be adopted, with the monitoring of PPP effects on sustainability factors. It is necessary, then, that institutions be in a position to guarantee the adoption of these measures and to promote "ex-post" follow-up (after decision). A SEA report is emphatic: "Assessments must avoid making recommendations for which implementation capacity does not exist" [26] (p. 53). Due its strategic conception, the role, the action mode and the outcomes of SEA are extremely linked to the institutional context in which it develops [24]. The importance of this approach was delimited by a practitioner:

The institutional issue is something relevant in the sense of understanding what I would call a "sound institution", with proper health, which functions properly. The curious thing is that in literature-at least the one I had the most access, which is English and American-nor discuss it because, for them, the institutional question is solved. But for us [Brazil], no. We [Brazilians] do not understand the institution as a "locus" that plays a fundamental role in the formulation and, above all, in the implementation of policies. Our decision-makers, our policy-makers, understand institutions as a mere "locus" where a "bunch of people" works! For me, it is a critical point 
of this whole process. (Practitioner J)

Lack of institutional capacity plagues SEA in developing countries [14]. The SEA process needs to evaluate the qualification and operational capacity of institutions-public and private, entrepreneurs and government-who have the role of following up the SEA and the PPP after the decision (including in terms of mitigation and impacts repair). That is, the SEA should evaluate the institutional capacities to manage effects and opportunities [15]. Considering what it may mean for the consolidation of the outcome and conclusions of the SEA, this procedure should be considered a GP.

It was essential that institutions that were to be committed to the SEA process had the capacity to act on what was foreseen for them. It would be necessary to analyze the extent to which the institution could be strengthened so that it would in fact play its role as compliant with the rules and procedures necessary to guarantee that activity. It is essential that government institutions understand the work dimension and have the competence and ability to do this work. Not necessarily end-to-end, because one may have consultants collaborating, participating, but the process has to be being managed, or at least understood, as a whole, by government spheres. (Practitioner J)

One interviewee highlighted the employment of this GP in the SEA coordinated by him:

I did an institutional assessment of the environmental sector of the [Organ], because the [Bank] also required this and is very interesting in the process. Will the environmental sector of the institution receiving the loan be able to carry out all the environmental operations being proposed? So, I did the institutional capacity assessment. It was very important, because it was observed if there was lack of equipment, if it lacked personnel. It means to say: "The Bank is going to finance a number $\mathrm{x}$ of programs, but does the institution have a formal structure, both personal and equipment, to manage these programs and give the result?" (Practitioner F)

Notwithstanding its recognized relevance, reaffirmed here by the view of SEA team leaders, the evaluation of the institutional capacity of entities to follow up the SEA's recommendations has not received due attention in most Brazilian processes (or at least is not described in the respective final reports). It is therefore necessary to emphasize the need for this requirement to be incorporated into the Terms of Reference.

\subsection{GP 7-Approach Oriented to Participation and Interaction with Stakeholders}

The participation of stakeholders throughout the process has been considered one of the most evident GP in environmental assessments [4] [9] [11] [12] [22] [23] [27] [28]. The public activities in SEA should be done in a way that fosters 
knowledge, brings communities together, and empowers them to participate, but this is usually neglected or poorly conducted [29]. In a sample of 100 reports of SEAs, $52 \%$ showed a public participation process in strict compliance with the law; there was only occasional involvement of interested parties in $29 \%$ of the cases and in five SEAs there was no action in this regard [25]. In 20 Portuguese SEAs, $75 \%$ of the processes did not promote public participation in the scope phase and in all cases there was no stakeholder consultation [18]. However, there are also successful examples of public participation [11].

The participation of the population, which we call social control, is important. Who knows of their reality are they, and not us, because we are in other places. The assessment has to be discussed. I think that today, in Brazil, social participation is important in any decision-making process. (Practitioner F)

The rationale that justifies the adoption of participatory methods is thus described:

The question of consulting society has proved to be good practice at work. When we discussed the SEA method, the question of the importance of local society participation was already "in the baggage". Not only as an information provider, to seek more reliable information about the region, but also as an instrument of anticipation of negotiations. To the extent that the individual feels involved in the project, he/she understands that it is possible participate, contribute and try to change something, and that would give a very great advantage in the future when that action would be implemented, as he/she already had a certain closeness to this action. (Practitioner J)

Go to the base, listen to different social actors. The construction of the SEA started at the base, with actors from distinct segments, because the look of each one is quite different: if you are of the public power, if you are civil society, if you are of a settlement [of agrarian reform]. It was time to listen to their reality, what they thought. It was a way for people to think: "this is what I want it to be or I do not want it to be this way; to not stay like this, I'll have to change my habits, I'll learn other things". (Practitioner K)

One interviewee pointed out that not all social actors have the same degree of contribution to the process, but a broad range of participation is desired.

Among the stakeholders, technical teams actively participate from the outset and suggest-because they have knowledge-how to build the baseline of their own territory. We arrive "half a foreigner" in the territory, as a consulting team to do the work. Members of City Halls and state bodies are always very useful for us to focus on what are the critical factors and which indicators translate that. They have knowledge to help. In terms of general public participation, of other stakeholders, I think we get more in the end, 
more in the sense of criticizing or accepting. (Practitioner I)

Despite its notorious importance, the participation of stakeholders in SEA presents some difficulties to be overcome.

Adding new heads and new knowledge in such a process is interesting. Sometimes it can be complicated because you bring some people with very defined conceptions and not open to a dialogue, a conversation, and thus it can be complicated; it is more conflict than contribution, that is, it depends a lot on attitude. (Practitioner J)

Regarding the participation of the local population, I have not yet been able to obtain a satisfactory result in terms of instruments for this. We're still looking for this. Sometimes a seminar [of consultation] is organized as if it were a public hearing, there are fights, discussions, and that is not the goal. In our case, there was no fight; on the contrary, there were very positive aspects. But the process is certainly not yet mature. There is a way to go in this direction, but that I consider important-a good practice. (Practitioner G)

Although it represents GP as shown above, public engagement in SEA processes has been limited, resulting in a low degree of influence on decision making [27]. This fact, also verified in Brazilian SEAs [1] [4], shows that there is still a long way to go in making this GP a consolidated reality.

\subsection{GP 8-Sharing and Exchange of Information/Knowledge by Digital Means}

One of the factors limiting stakeholder participation in the SEA is the lack of information about the process [27], denoting the importance of communication between the actors for the success of the work. In environmental assessments a GP is to present clear, consistent, timely, precise, regular and ongoing communication [9]. It must support the participation of all parties and make documentation available to the interested public, through easy and free access. The greater the variety of information media employed, the greater the likelihood of reaching and influencing the various target audiences.

Among the communication media, Internet portals have become increasingly important. Capable of disseminating information in real time to a large number of people and virtually without geographical boundaries, these tools are also important by the capacity of interaction that they can offer the interested parties. The availability of information on specific online sites becomes an instrument of democratic access to the content of the assessment [4]. One interviewee made reference to this.

With regard to disclosure, if we did the SEA today, I would use another procedure. One of the interesting things about this program [a program that the interviewee participated in, implemented in another country] is that every project that receives funding opens a web page where the project 
is describing, the team, and the activities. If it is even more proactive it also establishes, for example, a bulletin that it periodically sends out to the public, to an email-list. Unfortunately I did not have this knowledge [during the SEA realized in Brazil] and we did not use it, and the disclosure had this limitation. If I had to do it today, I would work otherwise. (Practitioner J)

Several SEAs already use the presentation of information on pages of the world wide web, but in many cases the initiative does not allow exchange with the public. The GP, therefore, is not limited to dissemination in a virtual environment, but also should encompass the full potential of interaction within it, reducing the distance between practitioners and stakeholders [29]. The use of webinars, virtual conferencing, video- and photo-sharing, blogging, wikis, chat rooms, virtual worlds and instant messaging is also a possibility [30].

The idea is to use the internet as a permanent and, above all, proactive tool. It is not just having the website. The page is there, but it is completely reactive. If you do not use tools to mobilize people, mobilize society to go there to seek information, the information may, at any given time, disappear and no one will feel any difference. So, we need a proactive, interactive disclosure that brings the information. What the person is reading he/she can comment on, he/she may criticize, he/she may suggest, and this process be permanent. The English do this. I think this is fundamental. (Practitioner $\mathrm{J})$

Also in this GP there is much to improve. Communication strategies were insufficient in 18 out 20 Portuguese SEAs and only $25 \%$ of reports inform the public about the existence of a specific website for the assessment process [18]. Real-time communication, including through social networks, is a perspective that can leverage public participation in SEA processes, and deserves to be duly analyzed in future research.

\subsection{GP 9-Capacity Building (Training of Human Resources)}

In some countries, SEA is a consolidated tool and has a suitable contingent of technicians capable of leading or integrating drafting teams. However, in several other countries SEA does not have the same tradition and there is a clear lack of human material capable of developing assessment actions. This is the case in Namibia, where the lack of local critical knowledge points to the need to improve the experience and specialization in this field, promoting the qualification of starting professionals through coaching, tutoring or supervision by experienced practitioners [22]. In this sense, the role of SEA is recognized as an instrument of training and learning [31], a fact also verified in Brazilian conditions, although not in full or in the totality of the processes [1] [4]. Brazilian practice has provided some degree of institutional learning, but the result in individual and social learning is not substantive [2].

Human capital formation for SEA is a challenge and can have repercussions in 
terms of the adoption and expansion of the tool. A GP is to use the SEA processes themselves to empower people, including practitioners, PPP formulators, decision makers, or even the lay public, with a view to acting in future processes. For this, the SEA should be configured as a process of formation, through the adoption of an epistemological and methodological posture focused on participation and learning. This means adopting a "learning by doing" approach, based on real time SEA experience [14].

I would replicate the model we used-the idea of doing a learning process, of training. The capacity building process should move forward because it was an extremely successful experience. Bring into the training process the staff of government institutions that have responsibility for the process of conducting SEAs that might be done in the future-this is a good practice for me. It is the training of these personnel as multipliers of the process, especially in the scope of government institutions. (Practitioner J)

One respondent stressed the importance of disseminating knowledge about SEA among various social groups and stakeholders (and not just among current and potential practitioners) in order to capacitate and "empower" the public:

As our goal was to transform Strategic Environmental Assessment into a public policy instrument, a lesson learned and that should be applied to create a forum for discussion, a training course-at a distance or not-for people to empower themselves, both of the state and municipalities, as of social movements. (Practitioner $\mathrm{K}$ )

Although not the first purpose of the SEA, the improvement of skills and abilities to act in future processes makes the application of the tool a useful long-term benefit, which justifies its mention as GP. However, it is necessary to emphasize that the implementation of an SEA with this profile is surrounded by several difficulties and is not usually well accepted by the drafting team.

\section{Conclusions}

Considered one of the most common forms of knowledge management, GP are present in the most diverse areas of human activity. It is in essence an invitation to reapply knowledge that has already proved useful and effective in a similar context. In the SEA, the use of GP is an alternative widely mentioned in the literature as inducing improvements in process development, but few works have been devoted to describing measures that can fulfill this role. When they are mentioned, the literature usually portrays the researchers' unique view, which is not always supported by actual tool practice.

This study offers several recommendations to be followed aiming at the improvement of the SEA processes, either before or during the "field stage". First, the Term of Reference must be elaborated with extreme care, in a careful and at the same time flexible way, to allow the execution of the work with the variables that are peculiar to it. A good measure is to prepare it using the experience of 
practitioners.

The Term of Reference itself should predict and project the execution of a "good practice based" SEA, to be implemented in parallel to the PPP as two sides of the same coin. This joint effort ensures greater effectiveness for both and allows SEA to have a more pronounced influence on future decision making. One of the objectives of these two tools should be to assess the capacity of the institutions involved-both entrepreneurs and government agencies-to follow the recommendations generated, as well as to monitor the planned actions.

It is important that the contracting entity assumes a proactive role during the SEA, accompanying the development of the assessment, which will facilitate the implementation of the measures that will follow. In addition, the process will be better conducted and will present more consistent results if there is a follow-up of another SEA team, as a review body and quality control instrument. Practitioners should agree to this co-production work and encourage this to occur.

An SEA must be a platform of dialogue and collaboration. Perhaps this is the biggest GP in this type of environmental assessment. This means adopting a trans-disciplinary profile, with space to the stakeholder participation. In this sense, the widespread use of digital media is both an opportunity and a necessity. Last, but not the least, each SEA could be used to produce or qualify human resources capable of working in other SEAs, in a continuous system of capacity building.

The GP indicated are fully feasible and can be included in the methodological design of any SEA. In addition, they represent a valuable contribution to the improvement of future SEA processes, whether in Brazil or in other countries, especially because they are the result of consolidated experience in real cases of application of the tool.

\section{References}

[1] Margato, V. and Sánchez, L.E. (2014) Quality and Outcomes: A Critical Review of Strategic Environmental Assessment in Brazil. Journal of Environmental Assessment Policy and Management, 16, art. 1450011. https://doi.org/10.1142/S1464333214500112

[2] Montaño, M., Oppermann, P., Malvestio, A.C. and Souza, M.P. (2014) Current State of the SEA System in Brazil: A Comparative Study. Journal of Environmental Assessment Policy and Management, 16, art. 1450022.

[3] Pellin, A., Lemos, C.C., Tachard, A., Oliveira, I.S.D. and Souza, M.P. (2011) Avaliação Ambiental Estratégica no Brasil: Considerações a respeito do papel das agências multilaterais de desenvolvimento. [Strategic Environmental Assessment in Brazil: Debates Regarding the Role of Multilateral Development Agencies]. Revista Engenharia Sanitária e Ambiental, 16, 27-36 https://doi.org/10.1590/S1413-41522011000100006

[4] Silva, H.V.O., Pires, S.H.M., Oberling, D.F. and La Rovere, E.L. (2014) Key Recent Experiences in the Application of SEA in Brazil. Journal of Environmental Assessment Policy and Management, 16, art. 1450009. https://doi.org/10.1142/S1464333214500094 
[5] Gallardo, A.L.C.F., Duarte, C.G. and Dibo, A.P.A. (2016) Avaliação Ambiental Estratégica para o planejamento da expansão da cana-de-açúcar: Uma proposta de roteiro. [Strategic Environmental Assessment for the Planning of Sugarcane Expansion: A Script Proposal]. Ambiente \& Sociedade, 19, 67-94. https://doi.org/10.1590/1809-4422ASOC127007V1922016

[6] Vettoretto, L. (2009) A Preliminary Critique of the Best and Good Practices Approach in European Spatial Planning and Policy-Making. European Planning Studies, 17, 1067-1083. https://doi.org/10.1080/09654310902949620

[7] UNDP (United Nations Development Programme) (2007) Knowledge Management Toolkit for the Crisis Prevention and Recovery Practice Area. UNDP, New York.

[8] SDC (Swiss Agency for Development and Cooperation) (2013) Knowledge Management Toolkit. 2nd Edition, SDC, Berne.

[9] Joseph, C., Gunton, T. and Rutherford, M. (2015) Good Practices for Environmental Assessment. Impact Assessment and Project Appraisal, 33, 238-254. https://doi.org/10.1080/14615517.2015.1063811

[10] D’Auria, L. and Cinnéide, M.O. (2009) Integrating Strategic Environmental Assessment into the Review Process of a Development Plan in Ireland. Impact Assessment and Project Appraisal, 27, 309-319. https://doi.org/10.3152/146155109X480600

[11] Aschemann, R., Baldizzone, G. and Rega, C. (2016) Public and Stakeholder Engagement in Strategic Environmental Assessment. In: Sadler, B. and Dusik, J., Eds., European and International Experiences of Strategic Environmental Assessment: Recent Progress and Future Prospects, Routledge, Abingdon, 244-269.

[12] González, A., Thérivel, R., Fry, J. and Foley, W. (2015) Advancing Practice Relating to SEA Alternatives. Environmental Impact Assessment Review, 53, 52-63. https://doi.org/10.1016/j.eiar.2015.04.003

[13] JOão, E. (2005) SEA Outlook: Future Challenges and Possibilities. In: Schmidt, M., João, E. and Albrecht, E., Eds., Implementing Strategic Environmental Assessment, Springer, Berlin, 691-700.

[14] Hobbs, J. (2016) Toward Good Practice in SEA for Development Cooperation. In: Sadler, B. and Dusik, J., Eds., European and International Experiences of Strategic Environmental Assessment. Recent Progress and Future Prospects, Routledge, Abingdon, 154-173.

[15] OECD (Organization for Economic Co-Operation and Development) (2006) Applying Strategic Environmental Assessment: Good Practice Guidance for Development Co-Operation. OECD, Paris.

[16] Partidário, M.R. (2007) Strategic Environmental Assessment Good Practices Guide-Methodological Guidance. Portuguese Environment Agency, Amadora.

[17] Partidário, M.R. (2012) Strategic Environmental Assessment Better Practice Guide-Methodological Guidance for Strategic Thinking in SEA. Portuguese Environment Agency, Lisbon.

[18] Polido, A. and Ramos, T.B. (2015) Towards Effective Scoping in Strategic Environmental Assessment. Impact Assessment and Project Appraisal, 33, 171-183. https://doi.org/10.1080/14615517.2014.993155

[19] UNECE (United Nations Economic Commission for Europe) (2015) Good Practice Recommendations on Public Participation in Strategic Environmental Assessment. United Nations, Geneva.

[20] White, L.N. and Noble, B.F. (2013) Strategic Environmental Assessment Best Prac- 
tice Process Elements and Outcomes in the International Electricity Sector. Journal of Environmental Assessment Policy and Management, 15, Article ID: 1340001. https://doi.org/10.1142/S1464333213400012

[21] Olagunju, A. and Gunn, J.A.E. (2015) First Steps toward Best Practice SEA in Developing Nation: Lessons from the Central Namib Uranium Rush SEA. Impact Assessment and Project Appraisal, 33, 57-67. https://doi.org/10.1080/14615517.2014.941233

[22] Hipondoka, M.H.T., Dalal-Clayton, D.B. and Van Gils, H. (2016) Lessons Learnt from Voluntary Strategic Environmental Assessments (SEAs) in Namibia. Impact Assessment and Project Appraisal, 34, 199-213. https://doi.org/10.1080/14615517.2016.1192829

[23] Noble, B. and Harriman, J. (2008). Regional Strategic Environmental Assessment (R-SEA): Methodological Guidance and Good Practice. Alberta Environment, Edmonton.

[24] Noble, B. and Nwanekezie, K. (2017) Conceptualizing Strategic Environmental Assessment: Principles, Approaches and Research Directions. Environmental Impact Assessment Review, 62, 165-173. https://doi.org/10.1016/j.eiar.2016.03.005

[25] Lobos, V. and Partidário, M. (2014) Theory versus Practice in Strategic Environmental Assessment (SEA). Environmental Impact Assessment Review, 48, 34-46. https://doi.org/10.1016/j.eiar.2014.04.004

[26] Levett, R. and McNally, R. (2003) A Strategic Environmental Assessment of Fiji's Tourism Development Plan. Worldwide Fund for Nature/South Pacific Programme (WWF-SSP), Suva.

[27] Rega, C. and Baldizzone, G. (2015) Public Participation in Strategic Environmental Assessment: A Practitioners' Perspective. Environmental Impact Assessment Review, 50, 105-115. https://doi.org/10.1016/j.eiar.2014.09.007

[28] Sinclair, A.J. and Diduck, A.P. (2017) Reconceptualizing Public Participation in Environmental Assessment as EA Civics. Environmental Impact Assessment Review, 62, 174-182. https://doi.org/10.1016/j.eiar.2016.03.009

[29] Vespa, M., Sinclair, A.J., Boerchers, M. and Gibson, R. (2017) New Process, Same Doubts: Participants' Perceptions of Strategic Environmental Assessment in Western Newfoundland. Journal of Environmental Assessment Policy and Management, 19, Article ID: 1750004. https://doi.org/10.1142/S1464333217500041

[30] Sánchez, L.E. and Mitchell, R. (2017) Conceptualizing Impact Assessment as a Learning Process. Environmental Impact Assessment Review, 62, 195-204. https://doi.org/10.1016/j.eiar.2016.06.001

[31] Tetlow, M.F. and Hanusch, M. (2012) Strategic Environmental Assessment: The State of the Art. Impact Assessment and Project Appraisal, 30, 15-24. https://doi.org/10.1080/14615517.2012.666400 